\title{
Using Partial Correlation Coefficient to Assess the Importance of Quality Attributes: Study Case for Tourism Romanian Consumers
}

\author{
Olimpia-Iuliana Ban and Victoria Bogdan
}

\begin{abstract}
The importance-performance grid is a marketing instrument used to optimize the attributes of products in order to increase the consumers' satisfaction. A special place for debates is represented by the way in which the importance of attributes is determined, the direct research way having many weak points, among which we mention: it aggravates the application of the survey, the answers are already influenced by the perceived performance of the products, the answers are not authentic or they are too polite so that the values obtained are high and the inter-item differences are little and pointless etc.

The aim of this paper is to test a mathematic method recommended by the literature in the field, in order to indirectly determine the importance of the attributes, starting from the evaluation of the performance of products in relation to global satisfaction.

Methodology contain: a survey through a questionnaire which recorded the importance assigned by candidates to the quality attributes and evaluated the performance of the touristic services considering the quality attributes; determined the importance of the attributes through the partial correlation coefficient, by correlating the attributes' perceived individual performance with the global satisfaction and compared the two matrixes pertaining to the information obtained by the two ways considering the marketing decisions.

The results obtained indirectly through the partial correlation coefficient substantially differs from the results obtained by directly investigating the importance of the attributes, in order to make marketing decisions. The present paper continues previous researches, in which we tested two methods meant to indirectly determine the importance of the attributes, the Spearman coefficient and the entropy calculus.
\end{abstract}

Index Terms-Importance-performance analysis, importance attributes, partial correlation, study case, tourism.

\section{INTRODUCTION}

A marketing instrument having the quality to be extensively used by theorists and practitioners is the Important-Performance Matrix (IPA) launched in 1977 by J. A. Martilla and J. C. James, which analyses the quality attributes of products/services considering the perceived importance and performance. IPA was applied in different fields, among them touristic services, in order to determine the selection factors for a hotel, to establish the critical attributes of the tourist guide's performance, to identify the

Manuscript received September 15, 2012; revised January 30, 2013. This work was supported in part by the Faculty of Economics, University of Oradea (financial support acknowledgment goes here).

Olimpia-Iuliana Ban is with the Department of Economics, Faculty of Economics, University of Oradea (e-mail: oban@ uoradea.ro).

Victoria Bogdan is with the Department of Finance-Accounting, Faculty of Economics, University of Oradea (e-mail: vbogdan@ uoradea.ro). competitivity factors of destinations or to draw up different strategies [1]-[3]. A critical point in building up the Importance-Performance matrix is represented by the determination of the importance of quality attributes.

The measurement of the attributes' importance in the IPA Importance-Performance matrix can be done as follows:

- Directly, by surveys. It has the following disadvantages: it makes more difficult to gather data by increasing the dimension of the survey, it makes longer the duration of answer recording, the scores have a very small inter-itemic variation with scores uniformly high, therefore useless [4], many times the answers are not trustworthy or are influenced by the punctual performance of the products/services considered [5]. For the indirect methods meant to establish the importance of the attributes bring in themselves more problems, the direct methods are still widely used. [6]

- Directly, by conjoint analysis. This method requires the application of a set of questions combining the characteristics of the product in different alternatives. This very useful method becomes unfeasible when it implies more than a few attributes, a situation often encountered in many cases or when the respondents perceive certain connections between characteristics.

- Indirectly, by mathematical methods by correlating the performance given to the attributes with the global satisfaction. Methods such as the following are used: the Pearson correlation coefficient [7] or the use of the Spearman coefficient [8].

- Indirectly, by regression coefficients and the multivariate regression [9]. These methods attempt to correlate the global satisfaction with the performance given to each attribute in order to detect the importance given to each attribute. The major disadvantages of this method are: the collinearity between the attributes [4] which leads to very poor results, the omission of a non-linear relationship between the global performance and that of each attribute fractionally [10]. Studies have shown that the negative effect of a product's low performance in the total evaluation of satisfaction is higher than the positive effect of an over the average performance [6]. The Spearman coefficient has yet the advantage of being able to be used for non-parametric data.

There have also been suggested other measurement methods, yet they contradict one another and they confer different results for the same case [8]-[11].

Alternatives of the Importance-Performance matrix have been created, framing improvements [6]-[11]. The most 
interesting ones are those highlighting the difference between importance and performance by drawing a diagonal given by the points of equality between importance and performance. In the IPA matrix framed by Abalo, the left upper part is enlarged and includes quadrant II, $1 / 2$ quadrant I and $1 / 2$ quadrant III and the attributes in this area are candidates for improvement. The area under the diagonal in the chart keeps the interpretation of Martilla and James' IPA. The difference is that, everything recording a higher score for importance than performance and it is located in the upper left side, is regarded as a candidate for improvement.

\section{Methodology}

The research took place in three stages:

- In the first stage there was a survey through a questionnaire which recorded the importance assigned by candidates to the quality attributes and evaluated the performance of the touristic services considering the quality attributes;

- The second stage determined the importance of the attributes through the partial correlation coefficient, by correlating the attributes' perceived individual performance with the global satisfaction;

- In the third stage the two matrixes pertaining to the information obtained by the two ways and the two matrixes were compared considering the marketing decisions.

Work hypothesis: by using Abalo's IPA matrix [6], the results obtained by directly investigating the importance of the attributes not substantially differs from the results obtained indirectly, in order to make marketing decisions. The market research and, implicitly, the building of the IPA matrix can be simplified by eliminating the questions regarding the importance of the attributes and determining the importance of the attributes by mathematical methods. The problem is not related only to simplification but to optimization, for such a performance generates am certain attitude towards the attributes, a certain perception of their importance, therefore it requires either the separate determination of importance and performance, in different moments or the indirect determination of importance.

- During March-April, 2010 a survey was conducted among the population of Oradea, Romania [12]. The sample was composed of a total of 1,060 people; sampling method chosen was the stratification method (margin of error of $3 \%$ ). The segmentation criterion used was age. The respondents were persons who received accommodation services in Romania at least once since 2007 till 2010.

The research goal was to investigate the level of Oradea inhabitants' satisfaction, with the quality of tourism services and the performance of service staff. The research instrument was a questionnaire with 21 questions, plus some questions related to socio-demographic aspects.

There were 19 attributes chosen for tourism staff, in correspondence with SERVQUAL, for which it was done the analysis of the importance given by respondents and the analysis of the perceived performance of the staff from Romania. A scale with five steps was used in this research, from "unimportant" to "very important".

TABLE I: PARTIAL CORRELATION

\begin{tabular}{|c|c|c|}
\hline Variables in correlation & & $\begin{array}{c}\text { Value of } \\
\text { coefficient }\end{array}$ \\
\hline r 19g.1 & $=$ & 0.0796 \\
\hline r 19g.12 & $=$ & 0.0878 \\
\hline r $19 \mathrm{~g} .123$ & $=$ & 0.0774 \\
\hline r 19g.1234 & $=$ & 0.0699 \\
\hline r 19g.12345 & $=$ & 0.0641 \\
\hline r 19g.123456 & $=$ & 0.0502 \\
\hline r 19g.1234567 & $=$ & 0.0587 \\
\hline r 19g.12345678 & $=$ & 0.0382 \\
\hline r 19g.123456789 & $=$ & 0.0358 \\
\hline r 19g.12345678910 & $=$ & 0.0350 \\
\hline r 19g.1234567891011 & $=$ & 0.0344 \\
\hline r 19g.1234567891011 12 & $=$ & 0.0280 \\
\hline r 19g.12345678910111213 & $=$ & 0.0365 \\
\hline r 19g.1234567891011121314 & $=$ & 0.0452 \\
\hline r 19g.123456789101112131415 & $=$ & 0.0449 \\
\hline r 19g.123456789 1011 1213141516 & $=$ & 0.0351 \\
\hline r 19g.1234567891011121314151617 & $=$ & 0.0251 \\
\hline $\begin{array}{l}\text { r 19g.1234567891011121314151617 } \\
18\end{array}$ & $=$ & 0.0184 \\
\hline
\end{tabular}

The results obtained indicated a hierarchy of the attributes from the point of view of the importance and a hierarchy of the attributes from the point of view of the perceived performance with regard to the tourism staff in Romania. (Table II, column 1 and column 3)

- The method chosen to determine the importance of the attributes is that of partial correlation between the performance perceived by for each attribute and the global satisfaction. For this method to be applied, it requires the transformation of data by their natural logaritmation [3].

After logaritmation, we obtain the value of coefficient " $r$ " for each attribute, how can be seen in Table I for Q8.19 Self-control. The value of coefficient " $r$ " indicates the importance assigned to attributes by partial correlation method. (Table II, column 2)

importance

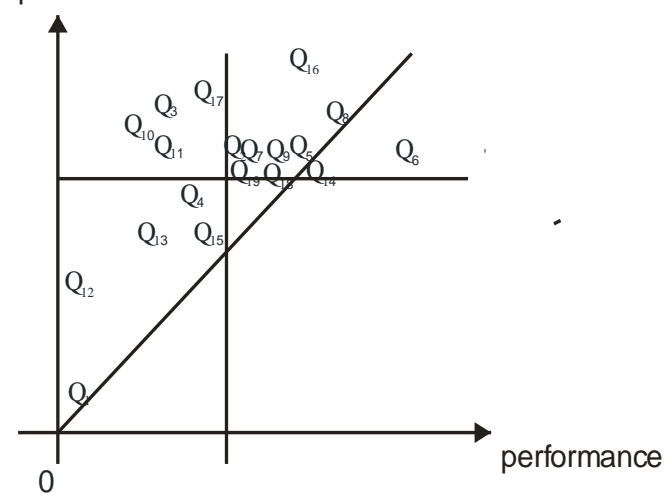

Fig. 1. Importance-performance grid obtained through direct research. 
- Based on data obtained, two importance performance matrixes were built according to the model framed by Abalo [6] the importance-performance matrix pertaining to data obtained directly (the attributes' perceived importance and performance) (see Fig. 1) and the importance-performance matrix pertaining to indirect determination of the importance by partial correlation and direct determination of the perceived performance in relation to the attributes mentioned (see Fig. 2).

TABLE II: IMPORTANCE AND PERFORMANCE OF ATTRIBUTES OBTAINED BY DIRECT DETERMINATION AND IMPORTANCE OF ATTRIBUTES OBTAINED BY PARTIAL CORRELATION

\begin{tabular}{|c|c|c|c|}
\hline \multicolumn{2}{|c|}{ Attributes according to their importance in the survey } & \multirow{2}{*}{$\begin{array}{l}\begin{array}{l}\text { Attributes according to their } \\
\text { importance determined } \\
\text { partial correlation }\end{array} \\
0.0348\end{array}$} & \multirow{2}{*}{$\begin{array}{l}\text { Attributes according to their } \\
\text { performance in the survey } \\
3.2\end{array}$} \\
\hline Q8.16 Kindness & 4.62 & & \\
\hline Q8.17 Responsibility & 4.58 & 0.0199 & 3.14 \\
\hline Q8.8 Communication & 4.53 & 0.0492 & 3.25 \\
\hline Q.8.3 Promptitude & 4.53 & 0.0128 & 3.12 \\
\hline Q8.10 Responsiveness to problems & 4.5 & 0.0099 & 3.06 \\
\hline Q8.11 Conscientiously & 4.46 & -0.0145 & 3.09 \\
\hline Q8.7 Ability to solve problems & 4.46 & -0.0744 & 3.17 \\
\hline Q8.2 Attention & 4.46 & -0.0556 & 3.16 \\
\hline Q8.5 Availability & 4.45 & -0.0109 & 3.2 \\
\hline Q8.9 Oral Expression & 4.45 & 0.0186 & 3.18 \\
\hline Q8.6 Physical Appearance & 4.43 & 0.0556 & 3.38 \\
\hline Q8.18 Sociability & 4.42 & 0.0161 & 3.19 \\
\hline Q8.14 Skills & 4.41 & -0.0206 & 3.23 \\
\hline Q8.19 Self-control & 4.4 & 0.0184 & 3.16 \\
\hline Q8.4 Professional knowledge & 4.38 & 0.0118 & 3.09 \\
\hline Q8.13 Flexibility & 4.26 & -0.0634 & 3.05 \\
\hline Q8.15 Elegance & 4.25 & -0.0142 & 3.13 \\
\hline Q8.12 Enthusiasm & 4.17 & 0.0612 & 2.95 \\
\hline Q8.1 Anticipate desires & 3.82 & 0.0428 & 2.96 \\
\hline Medium & 4.3989 & 0.0056 & 2.9868 \\
\hline
\end{tabular}

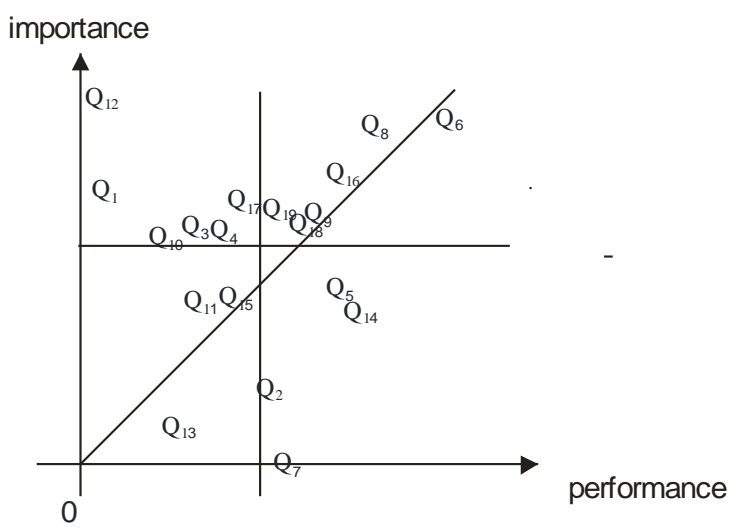

Fig. 2. Importance-performance grid obtained through partial correlation

\section{INTERPRETATIONS}

The IP grid constructed from the attributes evaluated directly as importance and performance, shows a concentration of 17 attributes (out of 19 attributes) in quadrant II and only two (Q6 and Q14) in quadrant I what mean keep up the good work.

According to Abalo's interpretation, in this case four attributes can be eliminated, unnecessary from the consumers' perspective: Q5- Availability; Q14- Skills; Q2Attention; Q7- Ability to solve problems and Q13- Flexibility could frame into "low priority".

The IP Matrix, built up with the data obtained directly (the performance perceived in relation to the attributes analysed) and the data obtained indirectly (the determination of the importance of attributes by partial correlation) shows the concentration of 11 attributes in quadrant II, of an attribute in quadrant I (Q6), of an attribute in quadrant III (Q13) and of four attributes in quadrant IV (Q5, Q14, Q2 and Q7).

Comparing the two matrixes, the fundamental difference is given by the four attributes which in the first matrix recommend to be supported and in the second their elimination is brought into attention. What is the reality? Starting from the idea that the direct answer does not reflect the reality, the importance assigned to the attributes being influenced by the performance associated to evaluated products/services, then, does the indirect method express more accurately the opinion of the respondents? The hypothesis asserting the getting of substantially different results is confirmed. Regarding the validation of certain results against others is debatable for, in their current form, there is a strong connection between the attributes proposed by SERVQUAL, here and there existing overlapping of meanings. For example, the consumers' decision could be to eliminate Q7 Ability to solve problems, as long as there is Q10 Responsiveness to problems. 


\section{CONCLUSIONS}

The hypothesis hasn't been confirmed, which brings into discussion the efficiency and credibility of results obtained indirectly, respectively the importance recording assigned to attributes in relation to global satisfaction. On the other side, SERVQUAL in the still very much used alternative requires radical revision, the intercollinearity of attributes being very high. Better results were obtained through the Spearman correlation coefficient, and the entropy calculus [13].

\section{REFERENCES}

[1] R. P. Bush and J. Ortinau, "Discriminating First Time and Repeat Patrons of a Retail Service Hotel Complex: A Case Study," in Marketing in an Environment of Change, Ed. by R. L. King. Southern Marketing Association, November 1986, pp. 281-85.

[2] Ch. N. Lin, L. F. Tsai, W. J. Su, and J. Ch. Shaw, "Using the Kano Two-Dimensional Model to Evaluate Service Quality of Resort Hotels," IJCSNS International Journal of Computer and Network Security, vol. 11, no. 5, May 2005.

[3] W. Deng, "Using a revised importance-performance analysis approach: The case of Taiwanese hot springs tourism," Tourism Management, vol. 28, pp. 1274-1284, 2007.

[4] D. R. Bacon, "A comparison of approaches to Importance-Performance Analysis," International Journal of Marketing Research, vol. 45, no. 1, pp. 55-71, 2003.

[5] W. J. Deng and W. Pei,, "Fuzzy neural based importance-performance analysis for determining critical service attributes," Expert Systems with Applications, vol. 36, pp. 3774-3784, 2009.

[6] J. Abalo, J. Varela, and V. Manzano, "Importance values for Importance-Performance Analysis: A formula for spreading aut values derived from preference rankings", Journal of Business Research, vol. 60, pp. 115-121, 2007.

[7] J. F. O'Leary and M. B. Adams, Community views concerning urban forest recreation resources, facilities and services, Chicago, Illinois: US Forest Service, North Central Forest Experiment Station, 1982.

[8] J. I. Crompton, and N. A. Duray, "An investigation of the relative efficacy of four alternative approaches to importance-performance analysis," Journal of the Academy of Marketing Science, vol. 13, no. 4, pp. 69-80, 1985

[9] A. L. Dolinsky and R. K. Caputo, "Adding a competitive dimension on importance-performance analysis: An application to traditional health care systems," Health Marketing Quarterly, vol. 8, no. 3/4, pp. 61-79, 1991.

[10] L. Slevitch and H. Oh, "Asymmetric relationship between attribute performance and customer satisfaction: A new perspective," International Journal of Hospitality Management, vol. 29, pp. 559-569, 2010.

[11] H. Oh, "Revisiting importance-performance analysis," Tourism Management, vol. 22, pp. 617-627, 2001.
[12] O. Ban and L. Popa, "Guest services quality assessment in tourism, using an attributes scale," in Proc. Annals of International Conference, "European Integration - new challenges," $6^{\text {th }}$ Edition, Oradea, pp. 378-384, May 2010.

[13] O. Ban, "The Construction of Importance-Performance Grid in Tourist Services Research Without the Direct Determination of the Attributes Importance" in Proc. Annals of University of Oradea, Economic Sciences, July 2012, pp. 474-480.

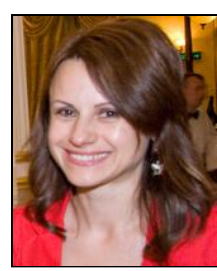

O. I. Ban was born in Oradea, on 23 February 1974. She received her Ph.D. degree in Economics (Marketing Specialized) in West University of Timisoara, Timişoara, Romania, in 2005. Currently Dr. Ban is working as associate professor in department of economics, faculty of economics, University of Oradea, Oradea, Romania from 2011. Dr. Ban has three publications, such as "Optimization and extensions of a fuzzy multicriteria decision making method and applications to selection of touristic destinations" in Expert Systems With Applications.

Dr. Ban is member of the organizing committee of the Scientific Sessions of the Faculty of Economics (1997 -2012), University of Oradea - Director of Section: Economy and Business Administration; member of the Scientific Committee of the Scientific Session of the Ph.D. in Economics, University of Oradea, Doctoral School of Economics, 2010-2011. She is a member of AGER (General Association of Romanian Economists) and member of AROMAR (Romanian Marketing Association). She has been a member of ESPON (European Observation Network on Territorial Development and Cohesion) since 2011. She has been a WSEAS reviewer since 2011.

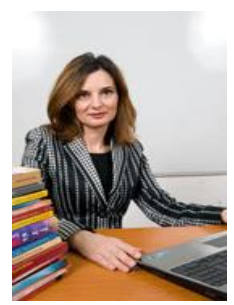

V. Bogdan was born in Oradea, on 24 October 1970 She received her $\mathrm{PhD}$ degree in Economics (Accounting), West University of Timisoara, Timisoara, Romania, in 2004. Now she is an associate professor in department of finance \& accounting, faculty of economics, University of Oradea, Oradea, Romania, from 2007. Dr. Bogdan has published many books and papers, such as "Financial reporting of group companies" in Editura Economica, Bucharest in 2011.

Dr. Bogdan is member of the organizing committee of the Scientific Events of Faculty of Economics since 2011, University of Oradea, Programme coordinator of section: Accunting and member of the Scientific Board of Journal Studia Universitatis "Vasile Goldis" Arad, Romania, Economic Sciences. Her main academic interests are: Basic Accounting, International Accounting and Consolidated Accounting and she is also a member of Quality Assurance Committee of Faculty of Economics, University of Oradea. Victoria Bogdan is a cerfied accountant and financial auditor member of the following professional organisations: CECCAR (Certfified Accontants Association from Romania), CAFR (Chamber of Romanian Financial Auditors) and AGER (General Association of Romanian Economists). 